OPEN ACCESS

Edited by: Leanne Ussher,

Bard College, United States

Reviewed by:

Michael Cooper,

Independent Researcher, Denver, CO,

United States

Marc Rocas-Royo,

Open University of Catalonia, Spain

*Correspondence:

David Rozas

drozas@ucm.es

Specialty section

This article was submitted to

Blockchain for Good,

a section of the journal

Frontiers in Blockchain

Received: 29 June 2020

Accepted: 15 March 2021

Published: 28 April 2021

Citation:

Rozas D, Tenorio-Fornés A and

Hassan S (2021) Analysis of the

Potentials of Blockchain

for the Governance of Global Digital

Commons.

Front. Blockchain 4:577680. doi: 10.3389/fbloc.2021.577680

\section{Analysis of the Potentials of Blockchain for the Governance of Global Digital Commons}

\author{
David Rozas $^{1 *}$, Antonio Tenorio-Fornés ${ }^{1,2}$ and Samer Hassan ${ }^{1,3}$ \\ ${ }^{1}$ GRASIA Research Group, Knowledge Technology Institute, Complutense University of Madrid, Madrid, Spain, \\ ${ }^{2}$ Decentralized Academy Ltd., Madrid, Spain, ${ }^{3}$ Berkman Klein Center for Internet \& Society, Harvard University, Cambridge, \\ MA, United States
}

In recent years, the increasing need for global coordination has attracted interest in the governance of global-scale commons. In the current context, we observe how online applications are ubiquitous, and how emerging technologies enable new capabilities while reshaping sectors. Thus, it is pertinent to ask: could blockchain technologies facilitate the extension and scaling up of cooperative practices and commons management in this global context? In order to address this question, we propose a focus on the most paradigmatic and widely successful examples of global cooperation: global digital commons. Examples of these are the digital resources maintained by large peer production communities, such as free/libre open source software and Wikipedia. Thus, this article identifies and analyzes the potentialities of blockchain to support the sustainability and management of global digital commons. Our approach draws on Elinor Ostrom's classic principles for commons governance, although revisiting and adapting these to the more challenging scope of global digital commons. Thus, in this work we identify the affordances which blockchain provides (e.g., tokenization, formalization of rules, transparency or codification of trust) to support the effective management of this type of global commons. As part of our analysis, we provide numerous examples of existing blockchain projects using affordances in line with each principle, as well as potential integrations of such affordances in existing practices of peer production communities. Our analysis shows that, when considering the challenges of managing global commons (e.g., heterogeneity or scale), the potential of blockchain is particularly valuable to explore solutions that: distribute power, facilitate coordination, scale up governance, visibilize traditionally invisible work, monitor and track compliance with rules, define collective agreements, and enable cooperation across communities. These affordances and the subsequent analysis contribute to the emergent debate on blockchain-based forms of governance, first by providing analytical categories for further research, but also by providing a guide for experimentation with the development of blockchain tools to facilitate global cooperation.

Keywords: algorithmic governance, blockchain, distributed systems, global commons, digital commons, Ostrom, peer production 


\section{INTRODUCTION}

This article explores the potentialities of blockchain linking it to the literature on the management of global digital commons. We draw firstly on Ostrom's classic governance principles (1990), which remind us how human communities have successfully selforganized to manage their common resources ("commons"). Such principles provide guidance for the conditions a community should respect in order to be sustainable, effective, and successful in the long-term in its commons management. Ostrom's principles were, however, derived from studies of small-scale local communities. In this article, we explore the role of emergent blockchain technologies as an opportunity to improve and scaleup communities' governance within a global scale. Concretely, we draw on the challenges of Ostrom's principles when adapted to global commons, identified by Stern (2011), in order to explore how blockchain technologies could help to overcome some of the limitations of Ostrom's principles. Our analysis focuses on global and digital commons, such as the digital commons generated and maintained by Wikipedia or large Free/Libre Open Source Software Software (FLOSS) communities, building on Commons-Based Peer Production (CBPP) literature.

\section{Commons Governance at a Global Scale}

Ostrom (1990) studied commons-based communitarian practices and identified eight design principles ${ }^{2}$ that contributed to the sustainable management of commons. These principles include diverse considerations such as the need to define boundaries in the community, having participatory and inclusive decision-making, or appropriate conflict resolution mechanisms. These principles remain a source of inspiration for the new global challenges. However, under the global scale of the resources and the communities which manage them, these principles require further re-consideration. Stern (2011) analyzed the degree to which Ostrom's design principles were transferable to the management of global commons. The conclusion was that, although they have considerable external validity, Ostrom's classic principles required adaptation when applied to global commons (Stern, 2011, 229). This conclusion is in line with the evaluation of the applicability of these principles to global commons undertaken by Ostrom herself (Ostrom et al., 1999, 281-282). Ostrom identified a set of challenges for global commons regarding governance, that include difficulties to scale up participation and define collective choices, challenges due to the cultural diversity, complications because of increasing rates of interdependency and change, and the fact that global commons depend on a single planet, from which there is no place to move.

Considering the challenges posed by global commons, in this article, we explore the potentialities of blockchain-based governance in a global context. Concretely, we look at the role of blockchain in the context of CBPP communities managing

\footnotetext{
${ }^{1}$ The commons are resources held in common, with shared ownership, and typically managed by a community under certain norms. It is distinct from both State or Market resource management. Classic examples include common lands or international waters, but also classical music (in public domain), a self-managed social center, the Internet, or Wikipedia.

${ }^{2}$ Section "Affordances of Blockchain for the Governance of Global Digital Commons" includes a definition of each of these principles.
}

global commons in the form of digital resources. The term CBPP, originally coined by Benkler (2002), refers to an expanding model of socio-economic production in which groups of individuals cooperate with each other to produce shared resources without a traditional hierarchical organization (Benkler, 2006). There are multiple, well-known examples of this phenomenon, such as Wikipedia, a project to collaboratively write a free encyclopedia; OpenStreetMap, a project to create free/libre maps of the World collaboratively; StackExchange, which are Q\&A communities which aim to provide accessible documentation; Thingiverse, which provides open 3D-printable digital designs; or FLOSS projects such as the operating system GNU/Linux, the web server Apache, the content management system Drupal and the browser Firefox. Given the popularity of Wikipedia and FLOSS, we will use these as recurring examples of large CBPP communities throughout the paper.

\section{Blockchain: Beyond Cryptocurrencies and Finance}

Since its appearance with the proposal of Bitcoin, the first distributed digital currency, blockchain technology has attracted attention for its ability to support a global scale currency and its potential to coordinate large communities without centralized control or a centralized infrastructure. Blockchain is a distributed and append-only database which, drawing on cryptography, enables coordination over the Internet without requiring central parties. Its origins are to be found in an article published anonymously under a pseudonym (Nakamoto, 2008). Drawing on a new data structure, the blockchain, problems such as doublespending - how can you ensure that digital currency is not spent twice? - could be solved in a decentralized manner. The result was that third parties, such as bank central servers in this case, could be avoided.

Considering these origins, blockchain technologies are, unsurprisingly, commonly associated with cryptocurrencies, new markets around emergent currencies, and overall with the disruption of finance. Nevertheless, the potential of blockchain goes beyond cryptocurrencies: it lies in its capacity to enable the implementation of novel properties at an infrastructural level in a fully decentralized manner. These properties have significant potentials, for example, for the development of tools that mediate and scale up governance processes.

To frame our analysis and in order to incorporate the identified challenges for global commons in our analysis, Section "Local Versus Global Commons" discusses the differences between the types of commons studied by Ostrom and global digital commons. Then, Section "Applications of Blockchain for Commons Governance" introduces the debate on blockchainbased forms of governance to situate the potential affordances of blockchain technology in this context. Next, Section "Affordances of Blockchain for the Governance of Global Digital Commons" analyzes the role played by blockchain technologies, drawing on the aforementioned affordances, for the governance of global digital commons. The result is the identification of a set of potentialities of blockchain technologies to tackle challenges (Ostrom et al., 1999, 281-282) regarding the scaling up of governance in managing global commons since, as 
the number of participants and heterogeneity of global CBPP communities increase, it becomes more difficult for them to organize and to reach agreements on rules and their enforcement. Section "Discussion and Conclusion" will discuss this result and provide some concluding remarks concerning the potential of blockchain to contribute to large CBPP communities in several ways.

\section{LOCAL VERSUS GLOBAL COMMONS}

For our analysis, we draw on Stern's (2011) identification of limitations of Ostrom's principles, which has been widely employed in the commons literature (e.g., Nayak and Berkes, 2012; Cox, 2014; Allen and Potts, 2016; Potts, 2019). In his analysis of the limitations of Ostrom's principles, Stern identifies a set of distinctive characteristics of the commons studied by Ostrom from which her principles were derived (Stern, 2011, 215). Developing from these characteristics, he identifies (Stern, 2011, 216-218) a series of differences between local and global commons that are relevant regarding governance. Stern's work, however, is focused on rival and global commons, such as global fossil supplies. Thus, in order to analyze the potentialities of blockchain for the governance of CBPP communities managing global digital commons, we need firstly to revisit these characteristics for the narrower scope of global digital commons.

According to Stern $(2011,215)$, the main characteristics of the commons studied by Ostrom, from which she derived her principles, are:

1. The commons studied by Ostrom are bounded at local to regional scale, in contrast to global commons. Thus, for the cases we are going to analyze, Stern's differences and limitations are aligned with those from our analysis.

2. The number of participants in Ostrom's case studies are in the tens to a few thousands, while in the global commons discussed by Stern, he assumes millions or even billions of actors involved. For our analysis, we consider large cases of CBPP communities, such as Wikipedia and large FLOSS projects such as Apache, Firefox and Drupal, that have from few millions to hundreds of thousands of participants (Fuster-Morell et al., 2016). Thus, we consider large CBPP communities, and incorporate Stern's limitations partially.

3. The third of the differences concerns the degradation of the commons, typical of rival commons. Digital commons, such as FLOSS or digital encyclopedias, are non-rival and, furthermore, sometimes anti-rival (Weber, 2004). Therefore, we do not include the limitations associated with this property in our analysis.

4. In the type of commons analyzed by Ostrom, the participants share common interests with respect to the management of the resource; while in the global commons discussed by Stern, their collective interests tend to diverge significantly. Tensions, regarding different interests, appropriation and co-optation by internal and external actors, are also a common problem in large
CBPP communities (e.g., De Filippi and Vieira, 2014; Birkinbine, 2015; Sandoval, 2019). Therefore, we incorporate Stern's identified limitations regarding this characteristic in our analysis.

5. The participants in the management of commons studied by Ostrom share a common cultural and institutional context; while in the global commons discussed by Stern they come from "all cultures, all countries, all political-economic systems, all political ideologies, and so forth" (Stern, 2011, 217). While large CBPP communities managing global digital commons develop a common cultural context (Fuster-Morell, 2014), the challenges regarding cultural diversity, also identified by Ostrom et al. (1999, 281-282) for global commons, are similarly present in large CBPP communities. Therefore, we incorporate this characteristic and its derived limitations in our analysis.

6. Learning from experience is a possible strategy in the local commons studied by Ostrom, while it is unfeasible for the type of global commons analyzed by Stern. We discard this limitation placed by Stern, since the literature shows how large CBPP communities managing global digital commons develop mechanisms and structures to facilitate the learning and extension of communitarian practices (e.g., Viégas et al., 2007; Forte et al., 2009; Fuster-Morell, 2010, 2014; Rozas, 2017).

Table 1, derived from a similar summary as in Stern (2011, 216), summarizes the characteristics identified by Stern, but

TABLE 1 | Differences between local commons (Ostrom, 1990), rival global commons (Stern, 2011) and the type of global digital commons which we will discuss in our analysis.

\begin{tabular}{|c|c|c|c|}
\hline & $\begin{array}{l}\text { Local commons } \\
\text { (Ostrom, 1990) }\end{array}$ & $\begin{array}{l}\text { Rival global } \\
\text { commons (Stern, } \\
\text { 2011) }\end{array}$ & $\begin{array}{l}\text { Global digital } \\
\text { commons }\end{array}$ \\
\hline 1. Scale & Local & Global & Global \\
\hline $\begin{array}{l}\text { 2. Number of } \\
\text { participants }\end{array}$ & Tens to thousands & Millions to billions & $\begin{array}{l}\text { Hundreds of } \\
\text { thousands to a few } \\
\text { millions }\end{array}$ \\
\hline $\begin{array}{l}\text { 3. Actors' } \\
\text { awareness of } \\
\text { degradation }\end{array}$ & $\begin{array}{l}\text { Resource use is a } \\
\text { conscious purpose }\end{array}$ & $\begin{array}{l}\text { Resource } \\
\text { degradation is an } \\
\text { unintended } \\
\text { byproduct of } \\
\text { intentional acts }\end{array}$ & $\begin{array}{l}\text { Not applicable for } \\
\text { digital commons }\end{array}$ \\
\hline $\begin{array}{l}\text { 4. Distribution } \\
\text { of interests and } \\
\text { power }\end{array}$ & $\begin{array}{l}\text { Benefits and costs } \\
\text { mainly internal in a } \\
\text { small group of } \\
\text { participants }\end{array}$ & $\begin{array}{l}\text { Significant } \\
\text { externalities } \\
\text { between } \\
\text { participants and } \\
\text { others }\end{array}$ & $\begin{array}{l}\text { Externalities between } \\
\text { internal participants } \\
\text { and external actors, } \\
\text { as in rival global } \\
\text { commons }\end{array}$ \\
\hline $\begin{array}{l}\text { 5. Cultural and } \\
\text { institutional } \\
\text { homogeneity }\end{array}$ & Homogeneous & Heterogeneous & $\begin{array}{l}\text { Heterogeneous, but } \\
\text { with a stronger } \\
\text { shared communal } \\
\text { culture than for rival } \\
\text { global commons }\end{array}$ \\
\hline $\begin{array}{l}\text { 6. Feasibility of } \\
\text { learning }\end{array}$ & Good & Limited & $\begin{array}{l}\text { Similar to that } \\
\text { described for local } \\
\text { commons, although } \\
\text { typically online } \\
\text { mediated }\end{array}$ \\
\hline
\end{tabular}


extends and adapts them to the narrower scope of global digital commons from which we will develop our analysis.

Having provided the ground to incorporate the limitations identified by Stern (2011) for Ostrom's principles to our context of analysis, we next discuss the general affordances of blockchain for commons governance.

\section{APPLICATIONS OF BLOCKCHAIN FOR COMMONS GOVERNANCE}

The use of blockchain technologies to mediate governance has been increasingly attracting the attention of social scientists (Risius and Spohrer, 2017; Cagigas et al., 2021). The result is a growing body of literature which revolves around discussions on whether blockchain technologies could foster the experimentation and rise of new forms of blockchain-based governance ${ }^{3}$.

Within the debate about the potentialities of blockchain-based governance we find, on the one hand, a myriad of perspectives characterized by a high degree of techno-solutionism (Morozov, 2013). According to them, given the right code, in this case in the form of smart contracts ${ }^{4}$ and $\mathrm{DAOs}^{5}$ (Decentralized Autonomous Organization), blockchains allegedly can solve Humanity's problems by finding the right algorithms. In fact, this is considered inevitable - following techno-determinism - since "anything that can be decentralized will be" (Johnston, 2014). These perspectives, however, tend to simplify or simply ignore the complexity which lies behind social organization. For example, they usually assume that hierarchies between the participants might vanish thanks to the disintermediation enabled by the use of decentralized technologies (e.g., Heuermann, 2015; Swan, 2015; Hayes, 2016). In other words, they tend to provide overreductionist accounts with regards to the distribution of power, failing to acknowledge issues such as the generation of oligarchies and the consequences of inherently embedding private market logics (e.g., Freeman, 2013; Shaw and Hill, 2014; De Filippi and Loveluck, 2016; De Filippi and Lavayssière, 2020). In this respect, we agree with Schneider (2019) in understanding decentralization not simply as a technical concept, but as a performative act whose socio-political consequences need further exploration, since the use of decentralized technologies does not inherently imply the decentralization of other outcomes,

\footnotetext{
${ }^{3}$ This paper focuses on the governance of global commons through or with blockchains, rather than the governance of blockchains, i.e., governance of the communities which develop and maintain blockchain projects. This is a relevant distinction since both debates are sometimes blurred. Conceptualizing a public blockchain like Bitcoin as a global commons, and therefore its governance as a commons-based process, is a promising approach to further our understanding of the social aspects behind the development of these decentralized technologies, but it is out of the scope of this paper.

${ }^{4}$ A Smart Contract (De Filippi et al., 2020) is a software program deployed in a blockchain environment and executed in a distributed manner once the underlying conditions are met.

${ }^{5}$ A Decentralized Autonomous Organization (Hassan and De Filippi, 2021) is a blockchain-based system that enables people to coordinate and self-govern themselves mediated by a set of self-executing rules deployed on a public blockchain, and whose governance is decentralized (i.e., independent from central control).
}

such as power. These types of issues, however, are not new. Parallels can be traced, for example, to the discourses which emerged during the popularization of access to the Internet in the 1990s, embedding ideas to "create a world that all may enter without privilege or prejudice accorded by race, economic power, military force, or station of birth" (Barlow, 1996). On this occasion, similar discourses are being generated, instead, around blockchain technologies.

On the other hand, a critical stand against these technosolutionist perspectives, particularly the pioneering work of Atzori (2015), has identified and criticized the limitations of such approaches. This critical stand, however, tends to consider traditional centralized authorities as inherently necessary to enable democratic governance. As a result, as we have previously argued (Rozas et al., 2021b), this critical stand has ignored the potential of some collectives to self-organize. Again, the issue is not new. Similar responses can be traced when reflecting on unregulated markets from positions that, as a result, aim to strengthen the role of traditional centralized authorities.

This lack of commons-oriented perspectives into the emergent debate of blockchain-based governance led us to consider incorporating the principles of commons governance present in self-organized collectives into the development of blockchainbased tools (Rozas et al., 2021b). Our aim was to contribute to building perspectives which neither rely on the logics of private markets, as implicitly assumed by these former perspectives, nor on the coercion of traditional centralized institutions, as in the case of the latter accounts. The result was the identification of six affordances ${ }^{6}$ (Hutchby, 2001), which constitute functional and relational aspects that frame the potentialities of self-organized collectives for agentic action, with regards to blockchain-based tools for commons governance (Rozas et al., 2021b, 8-20):

I. Tokenization: refers to the process of transforming the rights to perform an action on an asset into a transferable data element, a token, on the blockchain.

II. Self-enforcement and formalization of rules: refer to the process of embedding organizational rules in the form of smart contracts. As a result, firstly, there is an affordance for the self-enforcement of communitarian rules, such as those which regulate the monitoring and graduated sanctions in these communities. Secondly, this encoding of rules implies explicitation, since blockchain technologies require these rules to be defined in ways that are unambiguously understood by machines.

III. Autonomous automatization: refers to the process of defining complex sets of smart contracts as DAOs, which may enable multiple parties to interact with each other, even without human interaction. This is partially analogous to software communicating with other software

\footnotetext{
${ }^{6}$ The reasoning to frame our analysis through "affordances" relates to the need to navigate the Scylla and Charybdis of technological determinism and technological constructivism present in the field of science and technology studies (Juris, 2012). See Wellman et al. (2003), Boyd (2010), and Juris (2012) for examples in the use of affordances in the context of analysis in the Internet, social media and social movements, respectively.
} 
today, but in a decentralized manner, and with higher degrees of software autonomy.

IV. Decentralization of power over the infrastructure: refers to the process of communalizing the ownership and control of the technological tools employed by the community through the decentralization of the infrastructure they rely on, such as the collaboration platforms (and their servers) employed for coordination.

V. Increasing transparency: refers to the process of opening the organizational processes and the associated data by relying on the persistence and immutability properties of blockchain technologies.

VI. Codification of trust: refers to the process of codifying a certain degree of trust into systems which facilitate agreements between agents without requiring a third party, such as the federal agreements which might be established among different groups that form part of such communities.

These affordances drew on Ostrom's classic principles (1990), that were derived from her studies on communities managing local commons. In the next section, we discuss them in the context of large CBPP communities managing global digital commons, such as Wikipedia and large FLOSS communities, incorporating the challenges identified by Stern (2011) for each of Ostrom's design principles.

\section{AFFORDANCES OF BLOCKCHAIN FOR THE GOVERNANCE OF GLOBAL DIGITAL COMMONS}

This section will analyze the role played by blockchain technologies, drawing on the aforementioned affordances, for the governance of global digital commons. Thus, it is divided into eight subsections, one for each of Ostrom's governance principles. For each principle, we analyze how the blockchain affordances may contribute to the management of global digital commons, considering the challenges for global commons by Stern (2011). In addition, and again for each principle, we provide examples, first on how the affordance may be used in large CBPP communities (using Wikipedia and FLOSS as recurring examples), and second on how such affordance already operates in other contexts. The reason to use examples of these affordances "in action" out of the CBPP context is the lack of mature implementations of blockchain. Table 2 summarizes how the principles, the blockchain affordances and Stern's challenges relate to each other.

Thus, next we bring together the aforementioned affordances of blockchain for each of Ostrom's principles, contextualized within global digital commons.

\section{Clearly Defined Community Boundaries}

This principle refers to the need to have clear boundaries regarding who has rights and privileges over the community's commons, which becomes more challenging for global
TABLE 2 | Summary of the relationships between the affordances of blockchain technologies for the governance of global digital commons.

\begin{tabular}{|c|c|c|}
\hline $\begin{array}{l}\text { Ostrom (1990) } \\
\text { design principle }\end{array}$ & $\begin{array}{l}\text { Stern's (2011) challenges } \\
\text { in the application, } \\
\text { adapted to global digital } \\
\text { commons }\end{array}$ & $\begin{array}{l}\text { Related affordances of } \\
\text { blockchain (Rozas } \\
\text { et al., 2021b) }\end{array}$ \\
\hline $\begin{array}{l}\text { 1. Define boundaries } \\
\text { for resources and } \\
\text { participants }\end{array}$ & $\begin{array}{l}\text { - Size of participants group } \\
\text { and required granularity }\end{array}$ & - Tokenization (I) \\
\hline $\begin{array}{l}\text { 2. Devise rules } \\
\text { congruent with } \\
\text { conditions }\end{array}$ & $\begin{array}{l}\text { - Identifying the relevant } \\
\text { conditions } \\
\text { - Developing enforceable } \\
\text { rules for a global context }\end{array}$ & $\begin{array}{l}\text { - Self-enforcement and } \\
\text { formalization of rules (II) }\end{array}$ \\
\hline $\begin{array}{l}\text { 3. Allow most users } \\
\text { to participate in } \\
\text { developing rules }\end{array}$ & $\begin{array}{l}\text { - Size of participants' } \\
\text { groups and required } \\
\text { granularity }\end{array}$ & $\begin{array}{l}\text { - Tokenization (I) } \\
\text { - Decentralization of } \\
\text { power over the } \\
\text { infrastructure (IV) }\end{array}$ \\
\hline $\begin{array}{l}\text { 4. Hold monitors } \\
\text { accountable to users }\end{array}$ & $\begin{array}{l}\text { - Conflicts of interest } \\
\text { between parties } \\
\text { - Establishing monitors' } \\
\text { independence } \\
\text { - Need for global } \\
\text { monitoring } \\
\text { - Uncertainty about what to } \\
\text { monitor } \\
\text { - Greater difficulty } \\
\text { establishing accountability } \\
\text { across jurisdictions }\end{array}$ & $\begin{array}{l}\text { - Self-enforcement and } \\
\text { formalization of rules (II) } \\
\text { - Autonomous } \\
\text { automatization (III) } \\
\text { - Increasing transparency } \\
\text { (V) }\end{array}$ \\
\hline $\begin{array}{l}\text { 5. Apply graduated } \\
\text { sanctions }\end{array}$ & $\begin{array}{l}\text { - Authority to sanction } \\
\text { limited because of loosely } \\
\text { connected parties }\end{array}$ & $\begin{array}{l}\text { - Self-enforcement and } \\
\text { formalization of rules (II) } \\
\text { - Autonomous } \\
\text { automatization (III) }\end{array}$ \\
\hline $\begin{array}{l}\text { 6. Develop low-cost } \\
\text { conflict resolution } \\
\text { mechanisms }\end{array}$ & $\begin{array}{l}\text { - Loosely connected parties } \\
\text { - Heterogeneity in the } \\
\text { participants }\end{array}$ & $\begin{array}{l}\text { - Autonomous } \\
\text { automatization (III) } \\
\text { - Increasing transparency } \\
\text { (V) }\end{array}$ \\
\hline $\begin{array}{l}\text { 7. Ensure that } \\
\text { authorities permit } \\
\text { participants to devise } \\
\text { their rules }\end{array}$ & $\begin{array}{l}\text { - Need to affirmatively } \\
\text { facilitate local governance } \\
\text { - Need to facilitate the } \\
\text { learning and extension of } \\
\text { peer-to-peer practices }\end{array}$ & $\begin{array}{l}\text { - Self-enforcement and } \\
\text { formalization of rules (II) } \\
\text { - Decentralization of } \\
\text { power over the } \\
\text { infrastructure (IV) } \\
\text { - Codification of trust (VI) }\end{array}$ \\
\hline $\begin{array}{l}\text { 8. Establish nested } \\
\text { layers of organization }\end{array}$ & - Same as above cell & - Codification of trust (VI) \\
\hline
\end{tabular}

The table is inspired by a similar summary by Stern $(2011,220)$, but adapted to this narrower scope. For example, we have added a challenge concerning the definition of boundaries, which Stern $(2011,220)$ considers inapplicable, and we remove the additional principles (e.g., invest in science) as well as the challenges regarding principles (1990) which do not fit within this scope (e.g., because digital commons are non-rival/anti-rival).

communities because of its size ${ }^{7}$. In the case of large CBPP communities, such as Wikipedia and large FLOSS cases, boundaries are usually defined to coordinate contribution activities. Such boundaries are reflected, for instance, in

\footnotetext{
${ }^{7}$ Stern (2011, 221) argues that "defining boundaries for resources and appropriators is not a meaningful exercise for global commons, even though it is possible to treat political jurisdictions as boundaries for the enforcement agreements made by sovereign authorities." However, for the case of global digital commons discussed in this article, we incorporate Ostrom's first principle in our analysis since these boundaries have been found relevant in large cases of CBPP (e.g., Forte et al., 2009; Jemielniak, 2016; Dulong de Rosnay and Stalder, 2020; Rozas and Huckle, 2021).
} 
the platforms employed to coordinate collaboration. The software usually defines permissions and rights to modify the commons managed (e.g., who can edit a protected article in Wikipedia) as well as the rules for participants to gain or lose permissions and transit between roles (e.g., who can accept changes in a FLOSS project). For example, in the case of Wikipedia, this demarcation was found when exploring the relationship between technical and social power (Forte et al., 2009; Jemielniak, 2014). Similarly, for large FLOSS communities, boundaries operate to participate in the production and management of FLOSS subprojects (Rozas and Huckle, 2021).

In this context, the capacity of blockchain for tokenization (I) provides new capabilities to experiment with the use of different types of tokens in collaboration platforms. In particular, the distribution of tokens allows for participation rights to be more easily and granularly defined, propagated and revoked. Blockchain tokens can represent both the participation in an organization and the voting rights and power of each actor. For example, tokens can be employed to define the rights of and support decision-making around collectively managed assets, such as a co-working space or the resources employed by a cooperative of taxi drivers (Voshmgir, 2019, 376; Eva Coop, 2021). The use of tokens to represent rights and power in blockchain systems is central in some blockchain frameworks such as Aragon, DAOStack or Colony (Karjalainen, 2020). Within them, programs can authorize or deny certain actions to users depending on the tokens they own or expend. Thus, these tokens may be used by communities managing global digital commons, such as Wikipedia, to represent the different users' roles and permissions, as well as the rules to obtain access to them.

\section{Congruence Between Rules and Local Conditions}

This principle defines that the rules that govern behavior or resource use in a community should be: flexible and based on local conditions that may change over time, and intimately associated with the characteristics of the resources, rather than relying on a "one-size-fits-all" regulation. As noted by Stern (2011), the challenge for global commons resides in identifying the relevant conditions in such a heterogeneous environment.

In a blockchain context, the required explicitation of rules (II) which is encompassed in the development of smart contracts has an impact on visibilizing otherwise invisible tasks, such as reproductive labor (Jarrett, 2014; Fuchs, 2018). Thus, it provides opportunities to make these rules more available and visible for discussion, and therefore increase the degree of reflection which may lead to a higher degree of adaptability. In fact, new projects focus on increasing the customization and adaptability of blockchain applications. For instance, SourceCred ${ }^{8}$ enables online communities to decide which contributions to recognize, and how are they

\footnotetext{
${ }^{8}$ See https://sourcecred.io, for an example of a reputation protocol for open collaboration.
}

valued. It provides a framework to automatically acknowledge contributions including online participation, e.g., from software repositories (Github), community chats (Discord), and forums (Discourse). Furthermore, it has developed explicit mechanisms for users to request acknowledgment for activities that are not yet automatically recognized. Thus, such software promotes an active discussion of the notion of value in the community, beyond that directly related to the digital commons themselves (Rozas et al., 2021a). Furthermore, it enables voices from different types of contributors to be heard and valued.

Also, it is worth noting that the first implementations of blockchain systems did not provide ample smart contract flexibility given the blockchain immutability, which could have affected the implementation of this principle. However, current implementations provide tools to overcome former limits and upgrade smart contracts as needed. Examples are the upgradeability ${ }^{9}$ of Aragon's DAO platform and Open Zeppelin's tools for smart contract updating ${ }^{10}$.

\section{Collective Choice Arrangements}

This principle defines that in order to best achieve the congruence called for in the previous principle, the members who are affected by these rules should be able to participate in their modification, and the costs of such modifications should be kept low. In line with Stern's (2011) review for global commons, allowing most users to participate in developing the rules is a huge challenge leading to the need to unpack this principle: which groups of participants should be involved in creating and modifying which rules? How might blockchain influence the relationship between social (e.g., users) and technical power (e.g., platform developers and owners)?

This principle connects to two of the affordances. Firstly, as in the case of the previous principle, the aforementioned capacity for tokenization (I) of blockchain technologies could be employed to readdress latent power relations in these communities. The result could help to increase the participation of members who have traditionally had less power, and to give greater visibility to the differences of power within a community. Secondly, it relates to the affordance provided by blockchain to decentralize the power over the infrastructure (IV).

The control over the infrastructure (e.g., servers) which sustains, for example, the main collaboration platforms (e.g., Wikipedia's), commonly emerges as a point of organizational tension, that entails constant negotiation to generate collectivechoice agreements (e.g., who can access and control Wikipedia's servers). When CBPP communities start to grow substantially, they normally try to decentralize control over this infrastructure, which is commonly achieved by incrementing the degree of formalization. For example, defining more explicit and rigid organizational processes, roles and even formal institutions, such as the Wikimedia Foundation (Forte et al., 2009; Jemielniak, 2014) and FLOSS associations (Rozas and Huckle, 2021) returning to our previous examples.

\footnotetext{
${ }^{9}$ See https://hack.aragon.org/docs/upgradeability-intro

${ }^{10}$ See https://docs.openzeppelin.com/learn/upgrading-smart-contracts
} 
In large FLOSS communities the "threat of forking ${ }^{11}$," for example, conditions the members or institutions holding more power, to be perceived as accountable and legitimate in the eyes of the community, and they commonly respond by limiting and distributing their power over time. Similar dynamics have been found in other large CBPP communities beyond FLOSS, such as Wikipedia (Tkacz, 2014; Jemielniak, 2016).

While, in technical terms, forking code has become a simple operation, forking the infrastructure remains a complex matter which is significantly costly in terms of effort. Indeed, when forks in FLOSS communities occur, those who decide to fork the code usually need to create a new infrastructure from scratch. The use of blockchain technologies offers, in this respect, a promising field of experimentation and exploration of potential changes in these dynamics. The inherent properties of blockchain technologies facilitate the forking of the whole infrastructure and even the communitarian rules which have been encoded in them. Thus, the decentralization of the infrastructure reduces the technical cost to fork the community, reducing the power within the community of those previously in control of the infrastructure. In other words, the "threat of forking" conditions the processes of negotiation since participants holding more power are expected to maintain a general direction of the project which acknowledges and includes the main desires of the community.

These examples allow us to imagine scenarios of the possible opportunities gained by decentralizing power over the infrastructure in CBPP. Blockchain technologies may shape these dynamics by offering a higher degree of pressure for negotiation on those holding more power in the community, and eventually it may foster permissionless innovation (Thierer, 2016). In fact, many current blockchain projects are indeed forks of original blockchains implementing different rules. Unlike in other FLOSS software, these forks do not only duplicate the code of the programs, but can also duplicate the existing community, data, and value (e.g., if you own a bitcoin before a fork happens, you will also own a 'forked-bitcoin' in the forked blockchain, retaining both the original bitcoin and the new one). The Hive fork of the original Steem blockchain is a recent relevant example of these community forks (Jeong, 2020). Steem is the blockchain supporting the Steemit social network, one of the most used blockchain applications (Jeong, 2020). In February 2020, the Tron Foundation acquired the company developing Steemit, and a large proportion of the blockchain tokens. This raised concerns about the centralization of power in the network, as the new owners could exclusively control the network using their tokens. The Hive is a community fork of the original Steem that aims to avoid such a concentration of power, and has successfully attracted most of the original platform users. Thus, blockchain technology seems to facilitate community efforts to fork a software and its community, increasing the decisionmaking power of online communities while decreasing the power of the infrastructure's owners.

\footnotetext{
${ }^{11}$ Forking, in FLOSS communities, occurs when participants take a copy of source code from one project and start a new, independent and distinct version of it. This may or may not cause the fragmentation of the community in two different projects. Thus, the "threat of forking" reflects the fear of such fragmentation to occur.
}

\section{Monitoring}

This principle concerns some participants in the community acting as monitors of behavior in accordance with the rules derived from collective choice arrangements. These participants should be accountable to the rest of the community. Stern (2011) argues that this principle remains essential for global commons, although it becomes more difficult to implement.

Several of the affordances of blockchain for commons governance remain potentially useful in the context of global digital commons. On the one hand, the affordances for self-enforcement (II) of smart contracts and, more widely, that of autonomous automatization (III) - without human mediation - provide further means to track and communally fiscalize new aspects of the organizational processes. Secondly, the blockchain affordance of increasing transparency (V) may enable higher accountability, and might lead to more peer-to-peer forms of monitoring. Peer-to-peer monitoring is usual in CBPP communities, as part of their strong culture of openness. This culture of openness also involves the opening of the data generated in the collaboration processes. This constitutes a useful means for CBPP communities to successfully carry out and scale up their processes of monitoring.

Thus, blockchain might facilitate the monitoring of community rules. On the one hand, smart contracts represent rules of the online communities, which may include automatic mechanisms for specific monitoring. On the other hand, all interactions are recorded in the blockchain and can be observed in real time by any party. This has already enabled users to detect and mitigate the effects of users behaving against the perceived community rules. For instance, in 2017 a hacker stole $\$ 32$ million worth of cryptocurrencies in Ethereum, exploiting a software vulnerability. As a first response, a group of users called "The White Hat Group" stole all the other accounts affected by the same vulnerability ( $\$ 208$ million), in order to avoid it being stolen by other hackers taking advantage of it. Afterward, they returned that money to their owners, once the vulnerability was fixed (Zetzsche et al., 2018).

The use of blockchain to support transparent and open peerreviewing (Ford, 2013) is another example of the applications of blockchain for community monitoring. This is seen in the blockchain-based system implemented by Tenorio-Fornés et al. (2019), intended to increase the quality and accountability of peer-reviewing practices in academia. The system relies upon three pillars supported by decentralized technologies (Tenorio-Fornés et al., 2019, 4637-4368). Firstly, an "open access by-design" approach to store publications. Secondly, more transparent decision-making regarding peer-reviewing practices. The system proposes the storage of metadata of the publication process, such as who the reviewers are and the changes between the different revisions, into a decentralized ledger. In this way, such interactions are time-stamped, tamper-proof and subject to communitarian monitoring. Thirdly, the system proposes an open reputation network of reviewers supported by blockchain, which would reward positive behavior and reduce and expose unfair or biased reviews. 
Therefore, large online communities can also use blockchain to automate certain rules and enable the monitoring of communitarian behavior transparently. In fact, existing large communities such as Wikipedia already make extensive use of transparent records to monitor user interactions, and automate a large part of the monitoring using bots, programmed with specific responsive automatic actions. Thus, blockchain may be useful to enhance this transparency, improve CBPP community monitoring, and its automation.

\section{Graduated Sanctions}

This principle states that participants not only actively monitor but also sanction one another when behavior is found to conflict with community rules. These sanctions against participants who violate the rules should be aligned with the perceived severity of the infraction. As with the case of monitoring, Stern (2011) argues that this principle is also essential for global commons, although it is more difficult to implement because the participants are more loosely connected. For example, the parties in conflict are likely to live in different countries with largely different cultural settings. How to define and execute sanctions in such contexts becomes a significant challenge.

The affordances of self-enforcement (II) and autonomous automatization (III) for blockchain-based governance for large CBPP communities managing digital commons offer, in this respect, several avenues of exploration. Smart contracts can be employed by these communities to automatically self-enforce the rules that regulate the graduated sanctions agreed in the community. Furthermore, this capacity for self-enforcement could be even more intense when considering DAOs. DAOs can take the initiative when certain events happen, and react autonomously upon circumstances or user actions. In other words, they increase the degree of impersonalization with regards to the application of the sanctions agreed by the community. The effects are unknown and could vary: from preventing the usual effect of reacting against the enforcer or "killing the messenger," to the triggering of frustration and impotence as has been the case with previous reactions against machines (Postman, 1993).

In this respect, we can find existing examples in which blockchain software implements community sanctions. For instance, Kleros is a blockchain project providing blockchainsupported courts. In these courts, a jury formed by community members would mediate community conflict resolutions, delivering blockchain-supported verdicts. Furthermore, projects implementing these blockchain courts such as Aragon Court, have specific rules to sanction misbehaving members of the jury, since the community can start a vote to remove their power in the jury. Thus, large online communities can both encode sanctions in their smart contracts (e.g., losing a privilege if the community agrees so) and use blockchain courts to sanction behaviors against the community rules.

\section{Conflict Resolution Mechanisms}

This principle specifies that members of the community should have easy access to spaces in which to resolve conflicts. As in the case of the principle regarding the graduated sanctions, the difficulties identified by Stern (2011) for global commons are derived from the challenges posed by these communities being more loosely connected than those studied by Ostrom.

In this respect, the affordances of increasing transparency (V) and autonomous automatization (III) might be valuable for the design of blockchain-based tools which facilitate the scaling up of conflict resolution mechanisms in these large communities. On the one hand, transparency is commonly employed by large CBPP communities as part of their conflict resolution mechanisms. One can think, for example, of the enormous amount of content which can be found in the discussion pages of Wikipedia; or in the issue lists of FLOSS communities. These large amounts of data are not usually solely related to the digital commons maintained, but also to the organizational processes which surround them. Such transparency facilitates access, participation and visibility of conflict resolution processes.

On the other hand, the employment of the aforementioned DAOs could lead to spaces in which conflicts are made explicit, between members of a DAO, across DAOs, and between DAOs and humans. This encourages communities to establish more explicit mechanisms for conflict resolution, which may be at least partially tackled by automated processes. In fact, Aragon is already working on creating digital jurisdictions for conflict resolution within, and across, DAOs.

As previously introduced in the graduated sanctions section, some blockchain projects are developing blockchain-supported courts and other arbitration mechanisms (Metzger, 2019). In the case of Aragon Court, there is a hierarchy of courts for conflict resolution. Primary courts are "low cost" (since they imply a small cost in cryptocurrency), although the system enables appeals to higher and more expensive courts if a party is not satisfied with the verdict. However, despite these developments, these courts are far from replacing standard courts of laws, nor do they tackle major conflicts. In fact, we often see the resolution of conflicts in blockchain projects themselves being discussed and resolved in more traditional online platforms, such as social networks, forums and blogs. At times, these conflicts have also been escalated to traditional state courts. For instance, in the ecosystem of Aragon, a conflict over funding allocation and contractual obligations between the Aragon Association and the company Autark ended up in the Swiss court ${ }^{12}$.

The blockchain-supported courts and similar conflict resolution mechanisms could lower the cost to solve conflicts within global communities, and provide transparency to the conflict resolution processes. Moreover, the sole discussion and definition of a legitimate conflict resolution mechanism in an online community can reduce the effects of the so called "Tyranny of Structurelessness" (Freeman, 2013), in which power dynamics are strengthened when no formal structure is provided. Thus, blockchain can offer additional conflict resolution mechanisms to the tools already in use by global communities managing digital commons.

\section{Local Enforcement of Local Rules}

This principle states that the local jurisdiction to create and enforce rules should be recognized by higher authorities. In the

\footnotetext{
${ }^{12}$ See https://defirate.com/aragon-autark/
} 
case of the commons studied by Ostrom, these higher authorities are commonly referred to as those of traditional institutions, such as states, regional or local governments. An example could be government officials who acknowledge the creation of local rules in the context of self-organized fishing communities. Parallelisms have been established in the case of digital commons, but referring to higher authorities as the most formal and centralized institutions which commonly emerge in these communities, such as the Wikimedia Foundation (Forte et al., 2009), or FLOSS associations (Rozas and Huckle, 2021), to continue with the previous cases. In the emergence of Wikipedia's autonomous WikiProjects, jurisdiction to devise their own local rules is acknowledged by the more central authorities of Wikipedia. Also, the local jurisdiction of sub-projects is acknowledged within the general project in FLOSS communities (Rozas and Huckle, 2021). This is in line with Stern's (2011) challenges within this global scope, regarding the need to affirmatively facilitate local governance and peer-to-peer learning.

This principle, hence, connects with several affordances of blockchain. First of all, with the capacity of blockchain to self-enforce rules (II) and its relationship to formalize and codify agreements to facilitate the scaling up of trust (VI). Continuing with our examples of Wikipedia and large FLOSS communities, such smart contracts could embed the agreements within the aforementioned WikiProject or FLOSS sub-projects, in ways which encode that the local aspects are only decided by participants belonging to such projects. In other words, if we think of these communities as networks, blockchain-based tools for commons governance might help local nodes of CBPP communities to more easily ensure, by code, that their local jurisdiction ${ }^{13}$ and enforcement of local rules are acknowledged by higher authorities as well as by other nodes.

Additionally, this principle relates to the decentralization of power over infrastructure (IV). In Section "Collective Choice Arrangements," several examples of this affordance were discussed regarding the increasing capacity for forkability and its relationship to social aspects. Similarly, in this scenario it can facilitate a higher degree of autonomy to the local spaces which emerge over time. In other words, the differences in forms of pressure may provide new conditions for the negotiations that relate to having their local contexts and jurisdictions acknowledged by higher authorities.

The use of blockchain in virtual reality projects such as Decentraland (Chaudhari et al., 2019) offers an intuitive example of how blockchain can be applied to facilitate local enforcement of local rules. In Decentraland, users can purchase virtual land. They can also modify virtual land, incorporate 3D elements into it and change the colors and textures of this virtual world. The owners are the only users allowed to modify the land, and to sell it to other users. These users can also participate in the decisions that affect the whole functioning of Decentraland, such as the rules regulating land auctions. Thus, blockchain can facilitate the autonomy of users and groups beyond this virtual reality example. For example, groups of users in large FLOSS

${ }^{13}$ In this context, we refer to jurisdiction as the area over which the members of the node have control (Sullivan, 2009). projects can receive crypto-currencies to develop a sub-project. Furthermore, blockchain can facilitate the autonomous handling of the funds by these groups. Examples of the autonomous management of funding are numerous in the blockchain space, for example in Gitcoin (Qayum and Razzaq, 2020), Aragon $\left(\right.$ Aragon Flocks $\left.{ }^{14}\right)$ and Ethereum $\left(\right.$ Moloch DAO $\left.{ }^{15}\right)$.

\section{Multiple Layers of Nested Enterprises}

The last of Ostrom's principles states that, by forming multiple nested layers of organization, communities can address issues that affect resource management differently at broader and very local levels in order to scale up their governance. This is in line with Stern's (2011) challenges within the global scope concerning the need to find effective combinations of institutional types which facilitate local governance and allow it to scale up. In the commons literature, such institutional types commonly rely on the notion of polycentrism, which refers to the co-existence of several centers of governance which blend the distribution of authority and power with effective coordination between these centers (Ostrom et al., 1961). The concept polycentric governance was originally coined for the study of the organization of government in metropolitan areas, and subsequently employed for the study of management of natural resources. However, this concept has been more recently employed to explain self-governance in communities managing the peer production of digital commons (Mindel et al., 2018), such as Wikipedia (Hartswood et al., 2014; Safner, 2016) and large FLOSS communities (Rozas, 2017, 313-316).

In this respect, the affordance of blockchain for the codification of trust (VI), implemented through interoperability, offers avenues for future exploration. In technical terms, interoperability refers to the property of a system to operate with other systems through a series of interfaces. Such interfaces codify the rules of interaction of different units, and thus codify part of the trust, facilitating interaction. Blockchain provides affordances to increase the degree of collaboration not only through the generation of interfaces, but also by providing a full communal infrastructure: a shared decentralized database. This process of codification of trust may simply refer to the individuals and their interactions, as in the case of the transactions of cryptocurrencies. However, it may also involve the agreements arranged between the different groups that form part of the community, fostering the capacity of these communities to scale up governance in polycentric ways. Thus, and returning again to our previous examples of Wikipedia and large FLOSS projects, one can envision tools designed to facilitate polycentric governance in CBPP communities in the form of different locally shaped platforms encoding agreements according to the local conditions of each group, such as WikiGroups and FLOSS sub-projects within the general project. These platforms could be autonomously governed by the participants who belong to each of the groups, but interoperate between them and with the general platform at a broader level through federal agreements.

\footnotetext{
${ }^{14}$ See https://aragon.org/blog/flock-funding-for-aragon-teams

${ }^{15}$ See https://www.molochdao.com/
} 
Cryptokitties (Min et al., 2019), a blockchain based collectable game where you can breed and trade virtual cats, offers an example of blockchain interoperability capabilities. First, as it uses a blockchain interoperable standard for non-fungible tokens such as collectables. Thus, these collectables can be traded and used in multiple applications that support this standard, that is they can be exchanged for others. Furthermore, given its popularity, several games have been developed in which you can play using your own cryptokitties. These games are grouped in the socalled KittyVerse (Min et al., 2019). Thus, global online communities managing digital commons may implement such interoperability among their communities using blockchain applications. This would enable the creation of federations of online communities, and enhance the exchanges and interactions among them.

\section{DISCUSSION AND CONCLUSION}

In this article, we have explored the potentialities of blockchain to facilitate and scale up the governance of large and global CBPP communities managing digital commons. As we have shown, there are numerous examples of blockchain communities that make use of practices that may be beneficial if adopted by these CBPP communities. These practices reinforce Nobel laureate Elinor Ostrom's principles (1990) for sustainable community governance, taking into account the adaptation of such principles for global commons (Ostrom et al., 1999; Stern, 2011). To sum up, we can observe that blockchain has the potential to contribute to large CBPP communities in multiple ways, helping to: distribute power, facilitate coordination, scale up governance, visibilize traditionally invisible work, monitor and track compliance with rules, define collective agreements, and enable cooperation across communities.

This article and the theoretical framework it relies on (Rozas et al., 2021b) contribute to linking commons literature with blockchain technologies. Previous literature includes: Cila et al. (2020), who draw on the aforementioned blockchain affordances to develop a framework with three mechanisms and six design dilemmas for blockchain-based platforms to support local forms of CBPP; Calcaterra (2018), who discusses how Ostrom's principles could be applied to DAOs; and Shackelford and Myers (2017), who review the applicability of Ostrom's principles focusing on the governance of blockchains (instead of with blockchains). Other authors, without including blockchain within their analyses, have explored how Ostrom's principles could be mathematized (Pitt et al., 2012, 2017) and applied to algorithmic governance (Clippinger and Bollier, 2014).

This work contributes to the emergent literature on blockchain-based forms of governance in several ways. First, it analyzes the challenges encompassed by the different nature of global digital commons, when compared to those from which Ostrom's principles were derived, while linking them with the role of blockchain. This analysis has allowed us to reflect on the role that blockchain-based technologies already play in existing blockchain projects, and their potential role in current large CBPP communities. Overall, blockchain technologies could facilitate coordination, help to scale up commons governance and even be useful to enable cooperation among various communities in interoperable ways. In addition, our analysis reveals that, when considering the challenges of managing global commons (Ostrom et al., 1999, 281-282), the role of blockchain is particularly valuable to explore solutions that tackle the scaling up of governance and the definition of global collective agreements within more heterogeneous conditions (Stern, 2011).

A better understanding of the capabilities of blockchain technologies to support global forms of commons governance will require, however, further empirical research. In fact, we strongly recommend those willing to develop blockchain tools to support CBPP to do so guided by research. Moreover, the development of such tools should be carried out handin-hand with the CBPP community participants, in order to avoid the multiple problems of top-down software building and algorithmic biases (O'Neil, 2016; Eubanks, 2018). This should enable the development of blockchain-based technology which incorporates particular social practices into the design. In other words, the development should be aware of the cultural context of each CBPP community, as well as aiming to place the people who have been traditionally marginalized by design in the center (Costanza-Chock, 2020). The aforementioned relationships between the blockchain affordances and the challenges for global commons summarized in Table 2, could be employed as analytical categories from which to start the codesigning of this type of tools (e.g., Cila et al., 2020; Rozas, 2020).

Blockchain technologies are still young, and it is still early to envision the applications and practices that will take hold within communities. Further experimentation will enable their study and monitoring to extract best practices and successful patterns that may be incorporated more easily and with lower risks into existing CBPP communities. In fact, the analysis of the current practices of existing blockchain communities (El Faqir et al., 2020) is an open research line which may provide fruitful results to draw from.

This article has focused on the potentialities of blockchain for the governance of global digital commons. The challenges concerning other types of global commons, such as oceans and the atmosphere, would require a different analysis which incorporates specific characteristics and challenges. Future work may also explore more systematically the limitations, drawbacks and risks posed by the use of blockchain in this overall global context. The use of the blockchain affordances as categories for analysis could be useful in order to identify such risks. For example, with regards to tokenization, it would be relevant to explore the risks posed by extreme quantification and data fetishism (Sharon and Zandbergen, 2017); with regards to increasing transparency, those risks related to the need to comply with the "right to be forgotten" (Stevenson, 2010); or with regards to formalization and self-enforcement of rules, the risks related to the tools leading to extreme strictness and intrusiveness (De Filippi and Hassan, 2016).

Commons-Based Peer Production communities render radically different values and practices when compared with 
those that operate within the hegemonic logic of markets. As we have aimed to show, blockchain may facilitate the experimentation of ways in which to scale-up such forms of cooperation. We hope this combination may open up new avenues for the extension of commoning practices, and the muchneeded cooperation in our world at these unsettled times.

\section{DATA AVAILABILITY STATEMENT}

The original contributions presented in the study are included in the article/supplementary material, further inquiries can be directed to the corresponding author.

\section{AUTHOR CONTRIBUTIONS}

DR coordinated the elaboration of the manuscript and participated in all the phases, including conceptualization, literature review, structuration, analysis, and overall writing of the article. AT-F participated in the conceptualization, structuration, analysis, and writing of the manuscript. In addition, he provided most of the blockchain examples used in Section "Affordances of Blockchain for the Governance of Global Digital Commons." SH supervises the project this manuscript is

\section{REFERENCES}

Allen, D., and Potts, J. (2016). How innovation commons contribute to discovering and developing new technologies. Int. J. Commons 10, 1035-1054. doi: 10. $18352 /$ ijc. 644

Atzori, M. (2015). Blockchain technology and decentralized governance: is the state still necessary? J. Gov. Regul. 6, 45-62. doi: 10.2139/ssrn.2709713

Barlow, J. (1996). A Declaration of the Independence of Cyberspace. San Francisco, CA: Electronic Frontier Foundation.

Benkler, Y. (2002). Coase's penguin, or, Linux and "The nature of the firm." Yale Law J. 112, 369-446. doi: 10.2307/1562247

Benkler, Y. (2006). The Wealth of Networks: How Social Production Transforms Markets and Freedom. London: Yale University Press.

Birkinbine, B. J. (2015). Conflict in the commons: towards a political economy of corporate involvement in free and open source software. The Political Economy of Communication 2, 3-19. http://www.polecom.org/index.php/polecom/article/view/35,

Boyd, D. (2010). "Social network sites as networked publics: affordances, dynamics, and implications," in A Networked Self: Identity, Community, and Culture on Social Network Sites, ed. Z. Papacharissi (Oxfordshire: Routledge), 47-66. doi: 10.4324/9780203876527-8

Cagigas, D., Clifton, J., Diaz-Fuentes, D., and Fernández-Gutiérrez, M. (2021). Blockchain for public services: a systematic literature review. IEEE Access 9, 13904-13921. doi: 10.1109/access.2021.3052019

Calcaterra, C. (2018). On-Chain Governance of Decentralized Autonomous Organizations: Blockchain Organization Using Semada (ID 3188374). Rochester, NY: Social Science Research Network.

Chaudhari, A. A., Laddha, D., and Potdar, M. (2019). Decentraland - a blockchain based model for smart property experience. Int. Eng. J. Res. Dev. 4:5.

Cila, N., Ferri, G., de Waal, M., Gloerich, I., and Karpinski, T. (2020). "The blockchain and the commons: dilemmas in the design of local platforms," in Proceedings of the 2020 CHI Conference on Human Factors in Computing Systems, Honolulu, HI. doi: 10.1145/3313831.3376660

Clippinger, J., and Bollier, D. (2014). From Bitcoin to Burning Man and Beyond: The Quest for Identity and Autonomy in a Digital Society. Amherst, MA: ID3 and Off The Common Books. part of, P2P Models, of which he is the Principal Investigator. In addition, he discussed the manuscript's general approach, reviewed the manuscript, contributed to parts of it across all sections and to the discussions and examples. All authors contributed to the article and approved the submitted version.

\section{FUNDING}

This work was partially supported by the project P2P Models (https://p2pmodels.eu) funded by the European Research Council ERC-2017-STG (grant no.: 759207) and by the project Chain Community funded by the Spanish Ministry of Science, Innovation and Universities (grant no.: RTI2018-096820-A-100).

\section{ACKNOWLEDGMENTS}

We are grateful to the editor and the reviewers for their constructive feedback on our manuscript. We would like to thank Vasilis Kostakis and Eve Guterman for their valuable comments, as well as Tabitha Whittall for her help in copyediting and proofreading this article. Finally, we would like to thank Alexandra Elbakyan (Sci-Hub) for her contribution to make scientific knowledge available for everyone.

Costanza-Chock, S. (2020). Design Justice: Community-Led Practices to Build the Worlds We Need. Cambridge, MA: MIT Press.

Cox, M. (2014). Understanding large social-ecological systems: introducing the SESMAD project. Int. J. Commons 8, 265-276. doi: 10.18352/ ijc.406

De Filippi, P., and Hassan, S. (2016). "Blockchain technology as a regulatory technology: from code is law to law is code," in First Monday. Note That This is Not an Argument for Code Being Law. 'The Blockchain and the New Architecture of Trust', Vol. 21. ed. K. Werbach (Cambridge: MIT Press), 153-160.

De Filippi, P., and Lavayssière, X. (2020). "Blockchain technology: Toward a decentralized governance of digital platforms?" in The Great Awakening: New Modes of Life Amidst Capitalist Ruins, eds A. Grear, and D. Bollier (Brooklyn, NY: Punctum Book). doi: 10.21983/P3.0285.1.00

De Filippi, P., and Loveluck, B. (2016). The invisible politics of bitcoin: governance crisis of a decentralized infrastructure. Internet Policy Rev. 5:32.

De Filippi, P., and Vieira, M. (2014). The commodification of information commons: the case of cloud computing. Sci. Tech. L. Rev. 16, 102-143. doi: 10.7916/stlr.v16i1.3991

De Filippi, P., Wraty, C., and Sileno, G. (2020). Glossary of Distributed Technologies. Available online at: https://policyreview.info/open-abstracts/smart-contracts (accessed November 18, 2020).

Dulong de Rosnay, M., and Stalder, F. (2020). Digital commons. Internet Policy Rev. 9:15. doi: 10.14763/2020.4.1530

El Faqir, Y., Arroyo, J., and Hassan, S. (2020). "An overview of decentralized autonomous organizations on the blockchain," in 16th International Symposium on Open Collaboration (OpenSym 2020), August 25- 27, 2020, Virtual conference, Spain (New York, NY: ACM), 8

Eubanks, V. (2018). Automating Inequality: How High-Tech Tools Profile, Police, and Punish the Poor. New York, NY: St. Martin's Publishing Group.

Eva Coop (2021). Eva. Coop Ridesharing. Available online at: https://eva.coop/ (accessed March 4, 2021).

Ford, E. (2013). Defining and characterizing open peer review: a review of the literature. J. Sch. Publ. 44, 311-326. doi: 10.3138/jsp.44-4-001

Forte, A., Larco, V., and Bruckman, A. (2009). Decentralization in wikipedia governance. J. Manag. Inf. Syst. 26, 49-72. doi: 10.2753/mis0742-122226 0103 
Freeman, J. (2013). The tyranny of structurelessness. Womens Stud. Q. 41, 231-246. doi: $10.1353 /$ wsq.2013.0072

Fuchs, C. (2018). Capitalism, patriarchy, slavery, and racism in the age of digital capitalism and digital labour. Crit. Sociol. 44, 677-702. doi: 10.1177/ 0896920517691108

Fuster-Morell, M. (2010). Governance of Online Creation Communities: Provision of Infrastructure for the Building of Digital Commons. Fiesole: Cadmus EUI.

Fuster-Morell, M. (2014). "Governance of online creation communities for the building of digital commons: viewed through the framework of the institutional analysis and development," in Governing Knowledge Commons, eds B. M. Frischmann, M. J. Madison, and K. J. Strandburg (Oxford: Oxford University Press), 281-311. doi: 10.1093/acprof:oso/9780199972036.003. 0009

Fuster-Morell, M., Salcedo, J. L., and Berlinguer, M. (2016). "Debate about the concept of value in commons-based peer production," in Internet Science. INSCI 2016. Lecture Notes in Computer Science, Vol. 9934, ed. F. Bagnoli (Cham: Springer), 27-41. doi: 10.1007/978-3-319-45982-0_3

Hartswood, M., Grimpe, B., Jirotka, M., and Anderson, S. (2014). "Towards the ethical governance of smart society," in Social Collective Intelligence, eds D. Miorandi, V. Maltese, M. Rovatsos, A. Nijholt, and J. Stewart (Cham: Springer), 3-30. doi: 10.1007/978-3-319-08681-1_1

Hassan, S., and De Filippi, P. (2021). Decentralized autonomous organizations (glossary of distributed technologies). Internet Policy Rev. Available online at: https://policyreview.info/open-abstracts/decentralised-autonomousorganisation (accessed November 17, 2020).

Hayes, A. (2016). "Decentralized banking: monetary technocracy in the digital age," in Banking Beyond Banks and Money: A Guide to Banking Services in the Twenty-First Century, eds P. Tasca, T. Aste, L. Pelizzon, and N. Perony (Berlin: Springer International Publishing), 121-131. doi: 10.1007/978-3-319-424 48-4_7

Heuermann, C. (2015). Governance 2.0: a Hayekian Approach to (r)evolutionary Self-Governance by Cryptocurrencies. Konstanz: University of Konstanz.

Hutchby, I. (2001). Technologies, texts and affordances. Sociology 35, 441-456. doi: $10.1177 / \mathrm{s} 0038038501000219$

Jarrett, K. (2014). The relevance of "Women's work": social reproduction and immaterial labor in digital media. Telev. New Media 15, 14-29. doi: 10.1177/ 1527476413487607

Jemielniak, D. (2014). Common Knowledge?: An Ethnography of Wikipedia. Palo Alto, CA: Stanford University Press.

Jemielniak, D. (2016). Wikimedia movement governance: the limits of a-hierarchical organization. J. Organ. Chang. Manag. 29, 361-378. doi: $10.1108 /$ jocm-07-2013-0138

Jeong, S. (2020). Centralized Decentralization: Does Voting Matter? Simple Economics of the DPoS Block chain Governance. Available online at: https://ssrn. com/abstract $=3575654$ (April 21, 2020).

Johnston, D. A. (2014). Everything Will Be Decentralized. San Francisco, CA: Medium.

Juris, J. S. (2012). Reflections on \#occupy everywhere: social media, public space, and emerging logics of aggregation. Am. Ethnol. 39, 259-279.

Karjalainen, R. (2020). Governance in decentralised networks. SSRN Electron. J. 35. Available online at: https://papers.ssrn.com/sol3/papers.cfm?abstract_id= 3551099 (accessed November 18, 2020).

Metzger, J. (2019). The current landscape of blockchain-based, crowdsourced arbitration. Macquarie L. J. 19, 81-102.

Min, T., Wang, H., Guo, Y., and Cai, W. (2019). "Blockchain games: a survey," in Proceedings of the 2019 IEEE Conference on Games (CoG) (London: IEEE).

Mindel, V., Tech, V., Mathiassen, L., and Rai, A. (2018). The sustainability of polycentric information commons. MIS Q. 42, 607-631. doi: 10.25300/misq/ 2018/14015

Morozov, E. (2013). To Save Everything, Click Here: Technology, Solutionism, and the Urge to Fix Problems that Don't Exist. London: Penguin.

Nakamoto, S. (2008). Bitcoin: A Peer-to-Peer Electronic Cash System. New York, NY: CoinDesk.

Nayak, P. K., and Berkes, F. (2012). Linking global drivers with local and regional change: a social-ecological system approach in Chilika Lagoon, Bay of Bengal. Reg. Environ. Change 14, 2067-2078. doi: 10.1007/s10113-012-0369-3

O’Neil, C. (2016). Weapons of Math Destruction: How Big Data Increases Inequality and Threatens Democracy. Portland, OR: Broadway Books.
Ostrom, E. (1990). Governing the Commons: The Evolution of Institutions for Collective Action. Cambridge: Cambridge University Press.

Ostrom, E., Burger, J., Field, C. B., Norgaard, R. B., and Policansky, D. (1999). Revisiting the commons: local lessons, global challenges. Science 284, 278-282. doi: $10.1126 /$ science. 284.5412 .278

Ostrom, V., Tiebout, C. M., and Warren, R. (1961). The organization of government in metropolitan areas: a theoretical inquiry. Am. Polit. Sci. Rev. 55, 831-842. doi: 10.2307/1952530

Pitt, J., Diaconescu, A., and Bollier, D. (2017). Technology for Collective Action. New York, NY: IEEE Technology and Society.

Pitt, J., Schaumeier, J., and Artikis, A. (2012). Axiomatization of socioeconomic principles for self-organizing institutions: concepts, experiments and challenges. ACM Trans. Auton. Adapt. Syst. 7, 1-39. doi: 10.1145/2382570. 2382575

Postman, N. (1993). Technopoly: The Surrender of Culture to Technology. New York, NY: Vintage Books.

Potts, J. (2019). Innovation Commons: The Origin of Economic Growth. Oxford: Oxford University Press.

Qayum, A., and Razzaq, A. (2020). "A self-evolving design of blockchainbased open source community - IEEE conference publication," in 2020 3rd International Conference on Computing, Mathematics and Engineering Technologies (iCoMET) (Sukkur: IEEE), 1-11.

Risius, M., and Spohrer, K. (2017). A blockchain research framework. Bus. Inf. Syst. Eng. 59, 385-409. doi: 10.1007/s12599-017-0506-0

Rozas, D. (2017). Self-Organisation in Commons-Based Peer Production. Drupal : "The Drop is Always Moving". Surrey: University of Surrey.

Rozas, D. (2020). "Affordances of decentralised technologies for commons-based governance of shared technical infrastructure," in Prospectives, 1, 1, Bartlett School of Architecture (London: University College of London). Available online at: https://journal.b-pro.org/article/affordances- of-decentralisedtechnologies-for-commons-based-governance/

Rozas, D., Gilbert, N., Hodkinson, P., and Hassan, S. (2021a). Talk is silver, code is gold? Beyond traditional notions of contribution in peer production: the case of Drupal. Front. Hum. Dyn. 3:618207. doi: 10.3389/fhumd.2021.618207

Rozas, D., and Huckle, S. (2021). Loosen control without losing control: Formalization and decentralization within commons-based peer production. J. Assoc. Inf. Sci. Technol. 72, 204-223. doi: 10.1002/asi.24393

Rozas, D., Tenorio-Fornés, A., Díaz-Molina, S., and Hassan, S. (2021b). When Ostrom Meets Blockchain: Exploring the Potentials of Blockchain for Commons Governance. Thousand Oaks, CA: Sage Open. doi: 10.1177/21582440211002526

Safner, R. (2016). Institutional entrepreneurship, wikipedia, and the opportunity of the commons. J. Institutional Econ. 12, 743-771. doi: 10.1017/s174413 7416000096

Sandoval, M. (2019). Entrepreneurial activism? Platform cooperativism between subversion and co-optation. Crit. Sociol. 46, 801-817.

Schneider, N. (2019). Decentralization: an incomplete ambition. J. Cult. Econ. 12, 265-285. doi: 10.1080/17530350.2019.1589553

Shackelford, S., and Myers, S. (2017). Block-by-block: leveraging the power of blockchain technology to build trust and promote cyber peace. SSRN Electron. J. 19:334. doi: 10.2139/ssrn.2874090

Sharon, T., and Zandbergen, D. (2017). From data fetishism to quantifying selves: self-tracking practices and the other values of data. New Media Soc. 19, 16951709. doi: $10.1177 / 1461444816636090$

Shaw, A., and Hill, B. M. (2014). Laboratories of oligarchy? How the iron law extends to peer production. J. Commun. 64, 215-238. doi: 10.1111/ jcom. 12082

Stern, P. (2011). Design principles for global commons: natural resources and emerging technologies. Int. J. Commons 5, 213-232. doi: $10.18352 / \mathrm{ijc} .305$

Stevenson, K. (2010). Delete: the virtue of forgetting in the digital age. Princeton, NJ: Princeton University Press. doi: 10.1108/rmj.2010.28120aae.001

Sullivan, L. E. (2009). The SAGE Glossary of the Social and Behavioral Sciences. Newcastle upon Tyne: SAGE.

Swan, M. (2015). Blockchain: Blueprint for a New Economy. Newton, MA: O'Reilly. Tenorio-Fornés, A., Jacynycz, V., Llop-Vila, D., Sánchez-Ruiz, A., and Hassan, S. (2019). "Towards a decentralized process for scientific publication and peer review using blockchain and IPFS," in Proceedings of the 52nd Hawaii International Conference on System Sciences, Maui, HI. 
Thierer, A. (2016). Permissionless Innovation: The Continuing Case for Comprehensive Technological Freedom. Arlington, VA: Mercatus Center at George Mason University.

Tkacz, N. (2014). Wikipedia and the Politics of Openness. Chicago, IL: University of Chicago Press. doi: 10.7208/chicago/9780226192444.001.0001

Viégas, F. B., Wattenberg, M., and McKeon, M. M. (2007). "The hidden order of wikipedia," in Online Communities and Social Computing. OCSC 2007. Lecture Notes in Computer Science, Vol. 4564, ed. D. Schuler (Berlin: Springer), 445-454.

Voshmgir, S. (2019). Token Economy: How Blockchains and Smart Contracts Revolutionize the Economy. Berlin: BlockchainHub.

Weber, S. (2004). The Success of Open Source, Vol. 368. Cambridge: Cambridge Univ Press.

Wellman, B., Quan-Haase, A., Boase, J., Chen, W., Hampton, K., Díaz, I., et al. (2003). The social affordances of the internet for networked individualism. J. Comput. Mediat. Commun. 8:JCMC834. doi: 10.1111/j.1083-6101.2003.tb 00216.x
Zetzsche, D. A., Buckley, R. P., and Arner, D. W. (2018). The distributed liability of distributed ledgers: legal risks of blockchain. SSRN Electron. J. 14, 1-43. doi: $10.2139 /$ ssrn. 3018214

Conflict of Interest: AT-F was employed by the company Decentralized Academy Ltd.

The remaining authors declare that the research was conducted in the absence of any commercial or financial relationships that could be construed as a potential conflict of interest.

Copyright (c) 2021 Rozas, Tenorio-Fornés and Hassan. This is an open-access article distributed under the terms of the Creative Commons Attribution License (CC BY).

The use, distribution or reproduction in other forums is permitted, provided the original author(s) and the copyright owner(s) are credited and that the original publication in this journal is cited, in accordance with accepted academic practice. No use, distribution or reproduction is permitted which does not comply with these terms. 